\title{
Complete Treatment of Food Waste using Vertical Carbonizer
}

\author{
Doo Hee Han
}

\begin{abstract}
Conventional food processor was used as compost or feed after solid-liquid separation by crushing and compression. However, feedstuffs became difficult due to the inability to prevent toxic substances, and composting was reluctant to use inappropriately and excessively salty. Therefore, using food waste as its own heat source in the drying process will reduce fuel costs and provide new food treatment methods. The food waste that is rich in fat and protein is distilled and dried, the solid material is used as livestock feed, and the condensate is completely recycled as an external carbon source of deodorant or sewage treatment plant. At this time, the excess solid component is pyrolyzed in a vertical type carburetor, and a combustible gas is produced and burned to be utilized as a heat source of the food drying apparatus. The pyrolysis temperature of the dried food waste for making flammable gas was maintained at $400^{\circ} \mathrm{C}$ and in this case, the harmful gas was below the environmental standard. By maintaining $1200^{\circ} \mathrm{C}$ during combustion, the risk of dioxin was eliminated. The vertical carbonization system can be used as a solid fuel additive, a black gray concrete additive, a soil additive and the like, while the hydrocarbon gas produced by pyrolyzing the solid structure effectively is used as a clean fuel to reduce the fuel cost. Condensate is used as an external carbon source for liquid fertilizers, deodorizers and sewage treatment. This device is not necessary when using incinerator waste heat. In a food waste disposal facility in an area without an incinerator, the fuel can be self-sufficient and effectively reduce fuel costs.
\end{abstract}

Keywords : recycling, organic waste, steam heating, food waste, animal food

\section{INTRODUCTION}

The moisture content of food wastes is highest in the agricultural wholesale market with $90 \%$ of the waste, and is relatively small due to good moisture removal from the restaurant. The $\mathrm{pH}$ of food wastes is low as 4.74 in food wastes discharged from restaurants. Table 1 shows the results of chemical composition analysis of each food waste source.

Table-I. Analysis of food waste by sources

\begin{tabular}{|c|c|c|c|c|} 
division & Restaurant & home & $\begin{array}{c}\text { Agricultural } \\
\text { wholesale } \\
\text { market }\end{array}$ & $\begin{array}{c}\text { Compost } \\
\text { raw } \\
\text { material } \\
\text { standard }\end{array}$ \\
\hline moisture(\%) & 76.9 & 80.0 & 90.0 & $\geq 60$ \\
\hline $\mathrm{pH}$ & 4.74 & 5.23 & 5.91 & $\geq 60$ \\
\hline $\mathrm{OM}$ & 88.0 & 83.4 & 77.7 & $\geq 60$ \\
\hline $\mathrm{T}-\mathrm{C}(\%)$ & 48.9 & 46.3 & 43.2 & $\geq 60$ \\
\hline
\end{tabular}

Revised Manuscript Received on July 22, 2019.

Doo Hee Han*, ITCRI, Chungwoon University, 113, Sukgol-ro, Michuhol-gu, Incheon, 22100, R.O.Korea. hanknu@ hanmail.net

\begin{tabular}{|c|c|c|c|c|}
\hline $\mathrm{T}-\mathrm{N}(\%)$ & 3.55 & 3.31 & 1.43 & $\geq 60$ \\
\hline $\mathrm{C} / \mathrm{N}$ ratio & 15.8 & 14.61 & 31.5 & $\geq 60$ \\
\hline $\mathrm{P} 2 \mathrm{O} 5(\%)$ & 0.98 & 1.21 & 0.22 & $\geq 60$ \\
\hline $\mathrm{K} 2 \mathrm{O}(\%)$ & 0.69 & 0.42 & 0.39 & $\geq 60$ \\
\hline $\mathrm{CaO}(\%)$ & 0.55 & 0.65 & 3.34 & $\geq 60$ \\
\hline $\mathrm{MgO}(\%)$ & 0.34 & 0.31 & 0.73 & $\geq 60$ \\
\hline $\mathrm{NaCI}(\%)$ & 3.36 & 4.84 & 0.78 & $\geq 60$ \\
\hline $\mathrm{Fe}(\mathrm{mg} / \mathrm{kg})$ & 154.37 & 647.3 & 1517.3 & \\
\hline $\mathrm{Zn}(\mathrm{mg} / \mathrm{kg})$ & 24.79 & 61.60 & 46.61 & $\leq 900$ \\
\hline $\mathrm{Pb}(\mathrm{mg} / \mathrm{kg})$ & 0.27 & 10.70 & 0.55 & $\leq 150$ \\
\hline $\mathrm{Cu}(\mathrm{mg} / \mathrm{kg})$ & 5.53 & 9.25 & 6.62 & $\leq 500$ \\
\hline $\mathrm{Cr}(\mathrm{mg} / \mathrm{kg})$ & 5.49 & 3.11 & 1.13 & $\leq 300$ \\
\hline $\mathrm{Cd}(\mathrm{mg} / \mathrm{kg})$ & 0.32 & 0.47 & 0.57 & $\leq 5$ \\
\hline $\mathrm{Ni}(\mathrm{mg} / \mathrm{kg})$ & 1.07 & 3.00 & 2.07 & $\leq 50$ \\
\hline
\end{tabular}

Since 2005, landfills of food waste have been prohibited and many recycling facilities have been built. However, compost and feed produced from recycled products were reluctant to use due to imbalance in supply and demand, immaturity, salinity, and toxicity. In the case of compost, it is necessary to acquire a manufacturing and selling permit. The remaining recycled materials become waste again, and new methods of treatment are sought, one of which is the recycling of thermal energy and the use of carbide. Studies on the treatment of organic wastes such as food waste have been researched steadily [1-10]. If food waste can not be used as compost or feed, it is suggested to recycle it as fuel $[11,12]$.The purpose of this study is to investigate the method of treating wastes by the vertical carbonization method which can dry the food wastes in the circulation of the internal airflow and carbonize the organic wastes and combustible wastes more reliably and economically.

\section{MANUFACTURING PROCESS IMPROVEMENT}

\section{A.Problems of prior skill}

Generally, the method used to treat various types of wastes is mainly a method of landfilling, fermentation drying, drying or burning. Among them, the landfill method is extremely limited due to contamination of the landfill or leachate or odor, which is not a fundamental solution for treating the waste. In addition, as a method of fermentation treatment, it takes a lot of time and effort to utilize as a compost, and odor is generated in a fermentation drying process. 
Since the salt content is large, there is a problem that it is not suitable to be utilized as compost immediately.

Particularly, there is a disadvantage in that there is a limitation in the kinds of wastes that can be subjected to such fermentation drying treatment among untreated wastes as a material capable of such fermentation drying treatment.

Examples of the drying treatment method include hot air drying, floating air drying, rotary kiln drying, and micron spray drying. All of these are mixed with outside air and injected into the inside of the room, and the exhaust gas of the inside air stream occupies a high specific gravity, which makes it difficult to treat the exhaust gas, thereby spreading air pollution. There is a disadvantage in that the combustion rate as a solid fuel is very low due to the loss of fuel due to external direct exhaust during the treatment and the internal airflow in which the dry substance floats due to the supply of external air during drying can not be absorbed. Since it is dried using a separate external heat source, the fuel cost is high and it is uneconomical. Even in the case of a dried material, it is difficult to recycle it due to its imbalance. The external contaminants generated in the drying process pollute the surrounding environment and are recognized as a dislike facility. In recent years, there has been known a technique of carbonizing various wastes by anaerobic or hypoxic pyrolysis for the purpose of solving such problems. In this case, a harmful exhaust gas is generated due to adoption of a combustion method by heat resistant mixing. A low concentration of carbon dioxide gas is generated, resulting in a decrease in the combustion rate resulting in a large fuel loss, resulting in a large fuel loss. The life of the high-temperature pyrolysis furnace is shortened. Even if the internal combustion gas is separated and burned, since the combustion is performed by mixing with a large amount of external air, a large amount of harmful combustion gas is discharged. Heat recovery is difficult due to mixed exhaust during drying, fuel loss is large, fuel cost is high, and economical efficiency is low.

\section{B. Technical Improvements}

The organic wastes are subjected to a drying treatment and the dried organic wastes are carbonized in a vertical continuous carbonizer to produce a reduced activated carbon or solid fuel. The combustion process in the boiler is carried out by using the remaining residual air stream generated in the drying process and the combustible dry gas generated in the carbonization process so as to be utilized as a heating source required in the drying process. This will solve the problem of external pollution and reduce fuel costs. Also, the carbide produced after the drying treatment and the carbonization treatment is produced in the form of activated carbon having good water absorption or solid fuel having a good burning rate, and the volume thereof can be greatly reduced as compared with the capacity of the combustible organic waste to be initially supplied. Vertical type continuous carburetor is adopted to regulate the amount of air to be supplied, thereby ensuring the necessary heat source and stable operation by controlling the temperature. This makes it possible to more efficiently produce the hydrocarbon gas. A level gauge is mounted on the top of the metering ejector to ensure proper transport and venting to eliminate excessive pressure ejection and enable progressive cooling venting.

\section{C.Carbonization Process}

In this process, activated organic waste is carbonized by regulated inflow of external air and complex pyrolysis in a vertical continuous carbonizer to produce activated carbon or solid fuel and discharge it in a reduced amount. The flammable dry gas produced during the carbonization process it is a carbonization process in which the combustion is blown so that it can be utilized as a heat source of heat in the heat treatment process.

First, the flammable organic waste dried in the drying process is introduced into the hopper of the injection screw by the level gauge, and the contents fed by the operation of the driving motor are supplied to the inlet of the stationary continuous carbonizer The vertical stirrer is rotated by the driving motor in place, the outside air is supplied to the inside of the diesel through the injection line, the rotary joint, the external air inlet passage, and the external air outlet through the blower When the electric ignition rod is operated, the contents are charged.

At this time, the contents are dropped in a state of being evenly dispersed by the rotating stirring wing, and the loading operation is interrupted while the proper amount is loaded by the input level gauge, and the carbonization process is performed. When the contents are mixed evenly by continuously operating the stirring blades and the scrapers in a state of being ignited by the supply and the electric ignition rods, the contents slowly start to be carburized and carbonized, and the carbonization process is sequentially repeated. At this time, the amount of the contents to be supplied to the inside is controlled by the operation of the scraper which rotates in the lower part by the rotation of the vertical type stirrer and the amount of the remaining amount of the contents remaining in the internal part, The internal carbonized gas generated during the above carbonization process is fed to the boiler via the carbonized gas induction line and is utilized as a heat source for combustion.

When carbonization treatment is repeatedly carried out as described above to perform carbonization treatment as much as necessary, the contents subjected to carbonization are discharged to the outside via the discharge port, and then discharged to a constant-amount discharge unit through a discharge unit,, The amount of the contents to be supplied to the quantitative ejector is checked by the ejection level gauge, and the supply and discharge amount is adjusted. During the storage in the quantitative ejector, the dry gas generated from the contents is supplied to the boiler. So that it can be used as a heat source for combustion. Fig. 1 summarizes the heat treatment process of carbonization and combustion. 


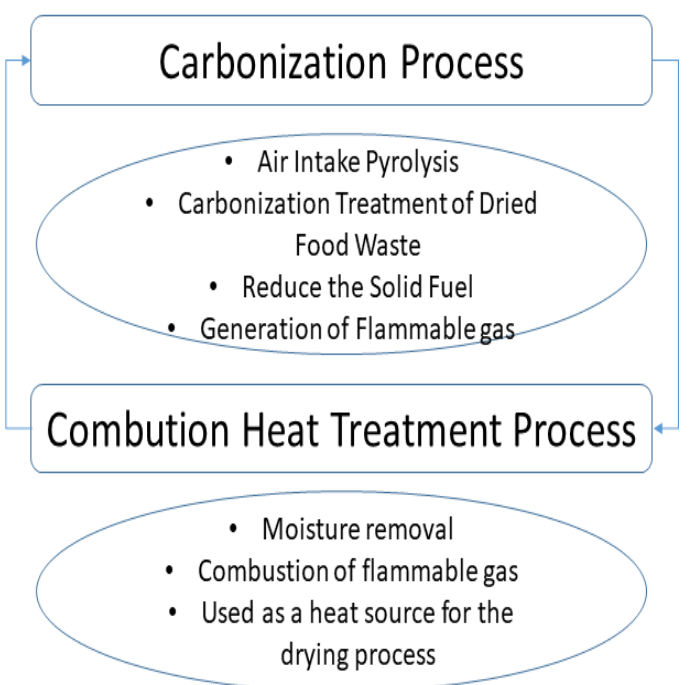

Fig. 1. Carbonization and combustion are heat treatment processes

\section{D.Combution heat treatment process}

The internal air flow except the internal air flow circulated in the drying process is blown and utilized as the combustion heat source and air in the boiler. The flammable dry gas generated during the carbonization process is blown to the boiler as a combustion heat source so that it can be utilized as a heating source of the dryer used in the drying process. That is, the internal air stream fed to the boiler via the internal airflow induction line is used as the combustion heat source and air in the boiler while the boiler is operated. The dry gas produced inside the vertical continuous carbonizer is fed to the boiler through the dry gas induction line. The dry gas generated from the metering ejector is sent to the boiler through a separate dry gas induction line. As a result, in the gas-air mixture induction device, the internal air flow by the internal air flow induction line and the external air by the combustion air supply line are maintained in a state suitable for combustion in a state where they are mixed with each other. Then, the heated air is supplied to the inside of the boiler, so that ignition and combustion by the burner are continuously performed and burned. Of course, the heat treatment process of the combustion process uses the whole internal air flow generated in the drying process as air as combustion heat source and air in the boiler, and also combustible dry gas generated during the carbonization process is also blown and burned as a combustion heat source in the boiler, so that it can be utilized as a heating source of the dryer used in the dryer.

At this time, the internal air stream generated in the dryer, the vertical dry carbonizer, and the dry gas generated from the metering ejector are utilized as fuel and air for operating the boiler. It is possible to preliminarily exclude the possibility of causing external pollution while burning and removing a desirable and bad smell in terms of fuel saving. Fig. 2 shows the structure of vertical carbonizer.

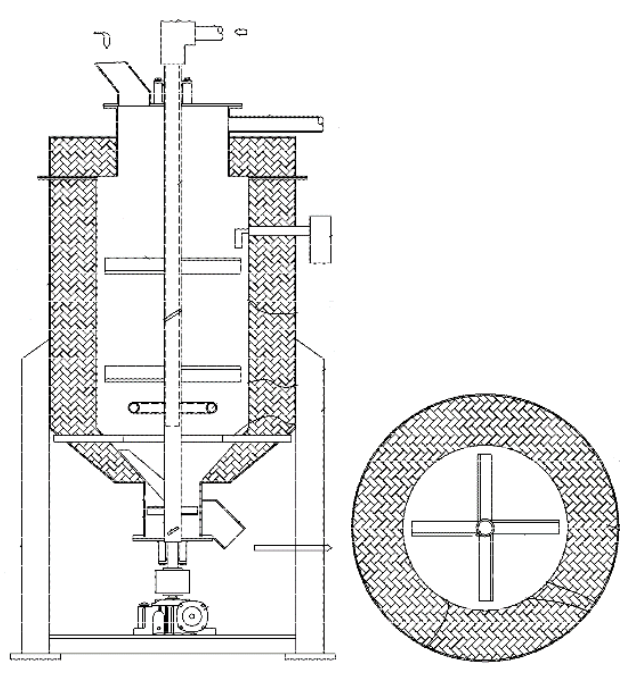

Fig. 2. Structure of vertical carbonizer.

\section{E.Development effect}

The organic wastes, which are highly perturbed wastes and flammable wastes, perform the drying process. The dried organic wastes are subjected to a carbonization process in a vertical continuous carbonizer, and the reduced carbonized material produces activated carbon and a solid fuel. Some or all of the residual internal airflow generated in the drying process and the combustible dry gas generated in the carbonization process are used to burn the boiler. It is possible to utilize it as a heating source required in the drying process, solve the problem of external pollution, and reduce the fuel cost.

In addition, the carbide produced after the drying treatment and the carbonization treatment is in the form of a solid fuel having a good absorption property and a good burning rate. It is possible to greatly reduce the volume of the organic waste as compared with the capacity of the organic waste to be initially supplied. In the case of the vertical combustion carbonizer used in the carbonization process, the stacking pressure is dispersed by the vertical multi-stage transport agitation. The material hardened by heat is intermittently pulverized by a stirring blade and a scraper to reduce the cause of the overload. The discharge is smoothly carried out, and in the carbonization process, the external air is controlled by the external air outlet to induce self-carbonization. It is possible to induce a pure gas under pressure by the loaded intermediate contents.

\section{VERTICAL CARBONIZATION PROCEDURE}

\section{A.Feature of machinery}

- Vertical structure minimizes machine installation area.

- Pyrolyzed at around $400{ }^{\circ} \mathrm{C}$ to generate flammable hydrocarbon gas.

- Flammable hydrocarbon gas burned at around $1200^{\circ} \mathrm{C}$, thereby exterminating the risk of dioxin.

- Remaining carbide can be used as a substitute for additive materials, black gray concrete additive and activated carbon. 


\section{B. Vertical carbonization equipment manufacturing}

A vertical pyrolysis combustion device for testing was fabricated. Stainless steel, which is resistant to corrosion, was used as a container material and a vertical stirring device was used. It was designed to generate combustible hydrocarbon gas by pyrolyzing at around $400{ }^{\circ} \mathrm{C}$ voluntarily, and it was made to be able to utilize it as a fuel by directly connecting it with the flue gas without collecting the generated combustible gas. The burning temperature of the furnace exceeded $850{ }^{\circ} \mathrm{C}$ to prepare for dioxin. Fig. 3 shows the shape of vertical carbonator for test.

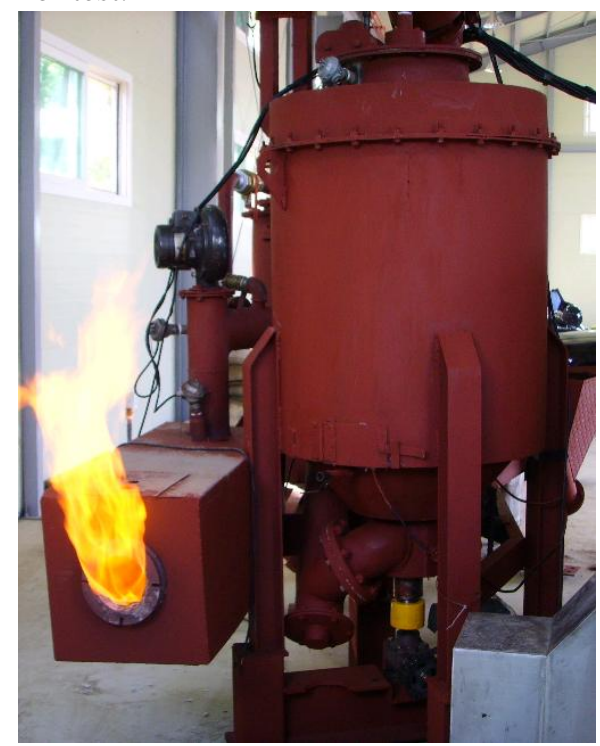

Fig. 3. Carbonator for test

The heat source of the installed food waste disposal unit was made to use mainly petroleum, and the cost of disposal increased sharply due to the oil price increase, which made it difficult to use the device continuously. Therefore, although the calorie is somewhat lacking, recycling the treated food waste as a heat source for a high-speed fermentation drying unit can reduce the fuel cost by $80 \%$. Manufactured pilot scale carbonization devices are roughly classified into raw material supply device, pyrolysis device and combustion device, which are accompanied by an automatic control device and a residue collecting device. The raw material supply is automatically transferred using a conveyor belt, and is automatically shut off when a certain amount is supplied to the inlet of the pyrolysis apparatus. The food waste solidified by the carbonization device is initially heated to $400^{\circ} \mathrm{C}$ by an oil burner, and the pyrolyzed gas is transferred to the combustion chamber and initially burned by the auxiliary combustion device. Some of the burned heat is returned to the pyrolysis chamber to heat the food waste solid fuel. When the pyrolysis chamber temperature reaches $400{ }^{\circ} \mathrm{C}$, the auxiliary heating burner is turned off, and the pyrolysis combustion continues automatically without an external heat source. The combustion chamber temperature is adjusted to maintain around $1200^{\circ} \mathrm{C}$.

The automatic operating conditions of the pyrolysis heat supply unit are summarized as follows.

- Automatic stopping device for $2 / 3$ rinsing of pyrolysis unit inlet

- The feedstock is automatically transported by the skewed feeder
- Attached temperature sensor to pyrolysis unit and combustion unit

- If the pyrolysis unit temperature is over $400{ }^{\circ} \mathrm{C}$,

- If the combustion chamber temperature is over $1200{ }^{\circ} \mathrm{C}$,

- Maximize pyrolysis efficiency by recycling combustion chamber heat to pyrolysis unit

- Automate all processes from raw material supply to residue collection

\section{C.Safety check of gas after combution}

Food waste is a mixture of various types of organic matter, so exhaust gases after combustion must be thoroughly examined. It is assumed that the gas to be burned is a hydrocarbon gas because it adopts a dry method to minimize the harmful gas. To verify the hazard, gas components were analyzed before and after combustion in the boiler room. The concentration of sulfur dioxide was sometimes more than expected, and precise analysis was required, but the deviation was so severe that the measurement error on the instrument could not be excluded. Table-II below is an analytical table of the measured gases.

Table-II: Closed dry pressurized carbonization system environmental review

\begin{tabular}{|c|c|c|c|}
\hline Division & Unit & $\begin{array}{c}\text { Emission } \\
\text { standard }\end{array}$ & $\begin{array}{c}\text { Average analytical } \\
\text { value }\end{array}$ \\
\hline $\mathrm{CO}$ & $\mathrm{ppm}$ & $\leq 200$ & 103.7 \\
\hline $\mathrm{NOx}$ & $\mathrm{ppm}$ & $\leq 150$ & 40.3 \\
\hline $\mathrm{SOx}$ & $\mathrm{ppm}$ & $\leq 70$ & 32.9 \\
\hline $\mathrm{HCl}$ & $\mathrm{ppm}$ & $\leq 40$ & 0.5 \\
\hline $\mathrm{F}$ & $\mathrm{ppm}$ & $\leq 2$ & 0.27 \\
\hline $\mathrm{Hg}$ & $\mathrm{mg} / \mathrm{sm}^{3}$ & $\leq 0.1$ & $\mathrm{ND}$ \\
\hline $\mathrm{Phenol}$ & $\mathrm{ppm}$ & $\leq 10$ & $\mathrm{ND}$ \\
\hline $\mathrm{NH}{ }_{3}$ & $\mathrm{ppm}$ & $\leq 100$ & $\mathrm{ND}$ \\
\hline $\mathrm{HCN}$ & $\mathrm{ppm}$ & $\leq 10$ & $\mathrm{ND}$ \\
\hline $\mathrm{AS}$ & $\mathrm{ppm}$ & $\leq 0.5$ & $\mathrm{ND}$ \\
\hline $\mathrm{Cr}$ & $\mathrm{mg} / \mathrm{sm}^{3}$ & $\leq 0.5$ & $\mathrm{ND}$ \\
\hline $\mathrm{Cd}$ & $\mathrm{mg} / \mathrm{sm}^{3}$ & $\leq 0.1$ & $\mathrm{ND}$ \\
\hline $\mathrm{Pb}$ & $\mathrm{mg} / \mathrm{sm}^{3}$ & $\leq 1.6$ & $\mathrm{ND}$ \\
\hline $\mathrm{Cu}$ & $\mathrm{mg} / \mathrm{sm}^{3}$ & $\leq 10$ & $\mathrm{ND}$ \\
\hline $\mathrm{Zn}$ & $\mathrm{mg} / \mathrm{sm}^{3}$ & $\leq 10$ & $\mathrm{ND}$ \\
\hline $\mathrm{Dust}$ & $\mathrm{mg} / \mathrm{sm}^{3}$ & $\leq 80$ & 5.5 \\
\hline $\mathrm{Smoke}$ & $\mathrm{degree}$ & $\leq 2$ & $\mathrm{ND}$ \\
\hline
\end{tabular}

\section{COMBINATION OF BATCH DRYER AND VERTICAL CARBONIZER}

\section{A.Bonding process}

The bonding process consists of a glaze process, a carbonization process, and a combustion process. The process is summarized in Fig. 4. 


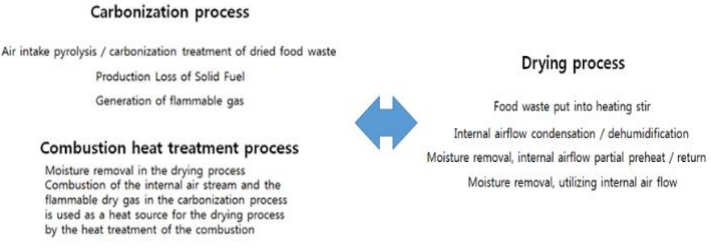

Fig. 4. The bonding process

\section{B. Manufacture of couple test equipment}

A vertical carburetor, a batch type dryer boiler, and the like were used to produce a test device for driving a vertical carbonizer and a high speed drying device in combination. The batch type high-speed drying apparatus is composed of an agitating device, a heating device, a heat exchanging and condensing water producing device, and an internal air circulation device. The stirrer is designed so that the two agitators are driven independently so that the food waste does not reach one side, and the heat jacket is installed so that the steam can efficiently heat the inside of the condensate and if the steam facility does not work. The heat exchanger and the condensate producing device are designed to quench when the high-temperature and high-humidity gas passes, to induce condensation, to discharge the condensed water to the outside, and to recycle the heated gas to the inside to assist the heating. If this process is continued, the solids become dry. The internal heating temperature is adjusted to maintain $80-100{ }^{\circ} \mathrm{C}$. The advantage of the batch drying system is that it is designed as an enclosed type, so there is almost no odor, only transparent solid condensate and solid content less than $10 \%$ of water content is used, and the solid component is used as feed or compost for dumpling and condensate is used as deodorant or liquid It was chosen as a recyclable device. With respect to composting, $1 \%$ of the salt content became effective, and it was utilized as a short - term feed by using additives such as mugwort, rather than using it directly as compost. The heat exchanger is a device that reheats the air cooled in the condenser by preheating the hot and humid air evaporated in the dryer and sends it to the fermentation dryer, which is installed next to the condenser at the top of the fermentation dryer. The heat exchanger consists of hot and humid air supply and exhaust lines. The heat exchanger vessel shall be made rectangular and shall have no leakage, and the heat exchange shall be capable of sucking and discharging the moisture evaporated by the dryer. The condenser is a device which cools the hot and humid air evaporated in the heat exchanger in the condenser, sends the cooled air back to the heat exchanger, and sends it to the fermentation dryer. It is installed next to the upper heat exchanger of the fermentation dryer. The condenser consists of an outer container, a condensate discharge line cooling water supply and discharge line, and a hot and humid air supply and discharge line. It should also be cylindrical and free of leaks, and the condenser should be capable of sucking and discharging the evaporated moisture content of the dryer.

Fig. 5 and 6 show the combined form. As a result of using this device, it was found that dried food wastes could be operated without external heat source when used as fuel, and they were found to be useful for the treatment of dry matter which can not be used as compost or feed. This device can be used for the treatment of poultry poultry caused by avian influenza and the like, or the treatment of fishery waste which is generated in the marine products market in large quantity. These poultry and aquatic products are excellent in protein and fat content, so it is preferable to use them as feed rather than compost.

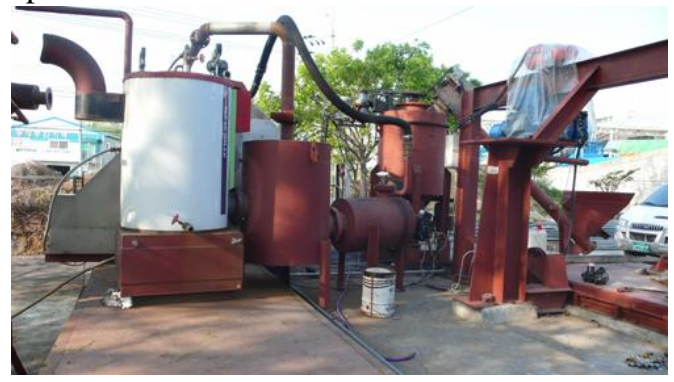

Fig. 5. Vertical Pyrolysis Combustor and Steam Boiler

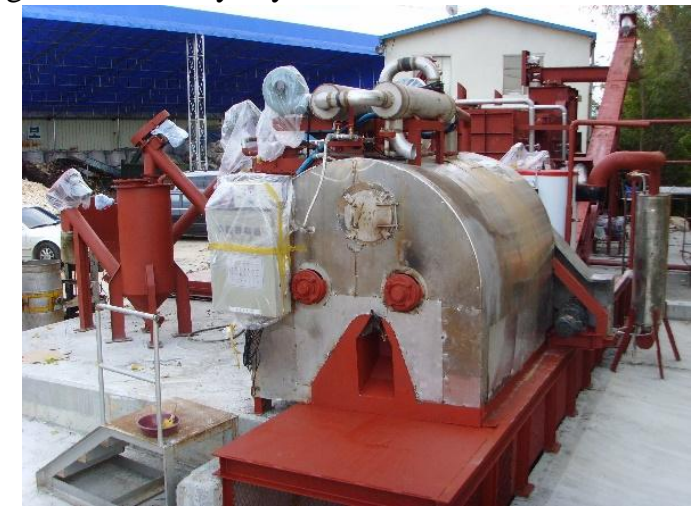

Fig. 6. Batch type high speed drying device connected with vertical pyrolysis combustion device

\section{COMPONENTS AND RECYCLING OF CONDENSATE}

The condenser combined with the heat exchanger was coupled to the batch type high speed drying device and operated normally. In addition, the operation of the dehumidifier could increase the effect of the condenser. The amount of condensate produced will be greater than $90 \%$ of the total amount of food waste if ignored and the amount of condensate produced will be large. Table-III shows the properties of the condensate.

Table-III: Water quality analysis of condensate

\begin{tabular}{|l|l|}
\hline Item & Condensate \\
\hline $\mathrm{TCOD}(\mathrm{mg} / \mathrm{L})$ & 20340 \\
\hline $\mathrm{SCOD}(\mathrm{mg} / \mathrm{L})$ & 20067 \\
\hline $\mathrm{T}-\mathrm{N}(\mathrm{mg} / \mathrm{L})$ & 81 \\
\hline $\mathrm{NO} 3-\mathrm{N}(\mathrm{mg} / \mathrm{L})$ & $2-3$ \\
\hline $\mathrm{NH} 3-\mathrm{N}(\mathrm{mg} / \mathrm{L})$ & 73 \\
\hline $\mathrm{T}-\mathrm{P}(\mathrm{mg} / \mathrm{L})$ & 10 \\
\hline Ortho-P(mg/L) & 10 \\
\hline $\mathrm{SS}(\mathrm{mg} / \mathrm{L})$ & $\mathrm{ND}$ \\
\hline $\mathrm{VSS}(\mathrm{mg} / \mathrm{L})$ & $\mathrm{ND}$ \\
\hline $\mathrm{TVFAS}(\mathrm{mg} / \mathrm{L})$ & 9340 \\
\hline
\end{tabular}




\section{A.Use of deodorant and liquor}

Last year there was a misfortune in which a large amount of poultry was buried due to avian flu. In Kunsan, the odor in the landfill has caused me to worry again. It was a deodorant obtained from food waste. A large amount of deodorant is also used in Gimpo landfill. The deodorizing effect of the condensed water is also used to remove the odor in the processing of the food waste, and it is also used to remove the odor by spraying on the storage hopper or the crusher. It can also be used as a liquid fertilizer, and has already been put to practical use in Japan and the like. The utilization rate of fertilizer is expected to be promising in light of the fact that the unit price of fertilizer is rising.

\section{B.Utilization as an external carbon source in the sewage treatment plantl}

Given the overall situation of domestic wastewater treatment, there is a way to comply with enhanced effluent quality standards while using existing facilities, not only will it reduce the cost of installing and operating a new advanced wastewater treatment facility, The existing facilities can be reused through a simple remodeling work, which can be expected to have the effect of maximizing sewage treatment efficiency. Condensate water can be used as an external carbon source in the treatment equipment of sewage and wastewater, which improves the existing activated sludge treatment method and improves nitrogen and phosphorus removal efficiency by adding carbon source from the outside. Through the process improvement, it is possible to economically and efficiently remove the eutrophication-causing substances such as nitrogen and phosphorus simultaneously with the organic matter, without the need of additional advanced treatment process in the existing wastewater treatment plant. And it can contribute to alleviate domestic environmental pollution problem.

\section{CONCLUSION}

A device combining a vertical carbonization unit and a batch-type high-speed drying unit was introduced. The entire process consists of a drying process and a carbonization process. The drying process is batch processed and the solid component is used as a new fuel through the carbonization process. Liquid ingredients are used as an external carbon source forsewage treatment plants, liquid compost and deodorant. carbonization process produces combustible gas by heating the dried food waste to about 400 degrees Celsius. This hydrocarbon gas is used directly in the drying process. The remaining carbide is used as a cover material for civil engineering works. Using this process, food waste can be completely processed. There is a risk of toxic substances when food waste is used as feed, and there is a side effect of salt when used as compost. This process can be a new alternative without these side effects.

\section{REFERENCES}

1. Doo Hee Han, Se-Jun Park, A Study on Compost of Food Waste by Salt Minimization, Journal of the Korea Academia - Industrial Cooperation Society, 2004, 5(2), 118-122.

2. Doo Hee Han, Development of Food Waste Fermentation System by Low Water-Ratio Salt Minimization, 2005, 6(2), 189-194.
3. Doo Hee Han, Recycling Apparatus of Organic Wastes by Direct Steam Heating, Proceedings of KAIS Spring Conference, 2007, 294-296.

4. Doo Hee Han, Development of Perfect Recycling Equipment for Sea Fish Waste , Journal of the Korea Academia - Industrial cooperation Society, 2010, 11(2), 614-619.

5. Doo Hee Han, Salt Reduction for Compositing of Food Waste, International Journal of Applied Engineering Research, 2014, 9(21), 9177-9184

6. Doo Hee Han, A Study on the Recycling of Lungfishes, Proceeding of The 2nd ICSMB2015.

7. Doo Hee Han, A Recycling Method of Rotten Fish Wastes, Indian Journal of Science and Technology, 2015, 8(22)

8. Emma Downing Wendy Carr, Food Waste, House of Commons Library, briefing paper number CBP07045, 10 June 2015.

9. Doo Hee Han, Liquid separator for livestock manure by dual raw separation equipment, Proceeding of ICCT2017, 2017.

10. Doo Hee Han, A Recycling Method of Food Waste by Drying and Fuelizing, Journal of Engineering and Applied Sciences, 2017, 12(14), 3599-3603

11. Byeong-Wook Min, Waste Materials Treating Process and Apparatus for Batch Type Drying and Vertical Type Carbonizing, Korean Patent No. 100845131, 2008.

12. Judy A Libra, Kyoung S Ro, Claudia Kammann, Axel Funke, Nicole D Berge, York Neubauer, Maria-Magdalena Titirici, ChristophFühner, Oliver Bens, Jürgen Kern, Karl-Heinz Emmerich1Hydrothermal carbonization of biomass residuals: a comparative review of the chemistry, processes and applications of wet and dry pyrolysis, Biofuels, 2011, 2(1), 89-124

\section{AUTHORS PROFILE}

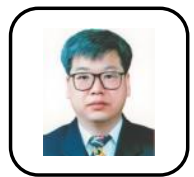

Doo Hee Han February 1994: Department of Physics, Kyungpook National University (Ph.D.) 1996 Present: Professor, Cheongwoon University Areas of Interest: Physical applications, waste, environment, recycling E-Mail: dhhan@chungwoon.ac.kr 